\title{
DOMESTIC CREDIT AND THE BALANCE OF PAYMENT DEFICIT: EVIDENCE FROM A HETEROGENEOUS PANEL OF FIVE SELECTED MENA COUNTRIES
}

\author{
Azeddine GHILOUS ${ }^{1 *}$, Adel ZIAT ${ }^{2}$ \\ ${ }^{1,2}$ Farhat Abbas University Setif, Setif, Algeria \\ *Corresponding author e-mail: azeddine.ghilousse@univ-setif.dz
}

\begin{abstract}
This study investigated the relationship between domestic credit and net foreign assets in the long run through the monetary approach to the balance of payments (MABP) for a panel of five selected MENA countries (Jordan, Egypt, Algeria, Morocco, Tunisia) during the period extending from 1980 to 2019. It employed the second-generation methods in panel data analysis to deal with cross-sectional dependence (CSD) and slope heterogeneity. According to the panel results for Common Correlated Effects Mean Group (CCEMG) and Augmented Mean Group (AMG) estimators, domestic credit has a significant negative impact on net foreign assets in the long run. The country-specific results for the AMG estimator strongly supported the MABP propositions in Jordan, Morocco, and to a lesser extent, in Egypt and Algeria. As for Tunisia, the results do not conform with what MABP predicted. The implicit conclusion is that an increase in domestic credit causes a continuous loss of net foreign assets in Egypt, Jordan, Morocco, and Algeria. Thus, monetary authorities should formulate an appropriate monetary policy to control the domestic credit creation as a mechanism toward improving the balance of payment (BOP) position. Furthermore, the policymakers should concentrate on other policy instruments to correct the BOP deficit rather than focusing on monetary tools, especially in Tunisia, where the findings showed that BOP was not a monetary phenomenon.
\end{abstract}

Keywords: Balance of Payments, Monetary Approach, Cross-sectional dependence, Heterogeneous Panel, Augmented Mean Group (AMG).

JEL classification: C31, C33, E12, E42

\section{INTRODUCTION}

BOP is a macroeconomic instrument that registers all transactions between a country and the rest of the world (Paun et al., 2013). Major accounts that form the balance of payments are the capital account, the current account and the financial account. In most developing countries, the BOP deficit is a common taxing problem, which raises questions about the causes of this problem and makes the search for possible solutions a priority. Many countries in the MENA region are also faced with this problem. For example, according to World Bank data, in 2019, the current account balance of Egypt, Jordan, Morocco, Algeria, and Tunisia recorded a deficit of 3.4, 2.3, and 4.1, 10,0 and 8.5 per cent of GDP, respectively. The International Monetary Fund gave thorough attention to the BOP equilibrium 
(Fleermuys, 2005). Developing countries are, thus, urged to pursue and manage the BOP equilibrium (Boateng \& Ayentimi, 2013).

The existing literature proposed the monetary approach as one of the main mechanisms to correct the BOP deficit. The basic assumption of the MABP is that a country's BOP is essentially a monetary phenomenon, and that BOP deficit can be corrected through skillful manipulation of monetary variables, especially domestic credit (Akpansung, 1998). Salam (1995) argument is that monetary authority abstention from generating money (which results in the creation of domestic credit) can automatically regulate the imbalance of the BOP. Thus, we can say that the MABP identifies domestic credit as both a cause and a cure for the BOP deficit; hence, knowledge and control of this variable are a required condition for targeting the appropriate monetary policy.

During the last few decades, the world economy has experienced increasing financial and socio-economic integration among countries, implying strong interdependencies between cross-sectional units. Thus, neglecting these effects in panel data analysis leads to inconsistent and biased results (Ho Deyos \& Sarafidis, 2006). In the empirical literature, cross-country studies, however few they may be, used the traditional techniques to analyse panel data that do not consider CSD; this includes Aghevli and Khan (1977) and Adamu and Itsede (2010). This work differs from others in that it employs second-generation techniques in panel data analysis that consider the slope heterogeneity and CSD to bridge this scientific gap and get more precise and robust results.

This paper sets to examine the long-run relationship between domestic credit and net foreign assets through the MABP model for a panel of five selected MENA countries to know whether domestic credit creation has played an important role in the BOP deficit in these countries. This work is foreseeable to contribute to the literature by providing a foundation to grasp the relationship between monetary policy and BOP disequilibrium in the selected MENA countries. Also, this study could avail as a reference for policymakers in dealing with the BOP problems. Beyond that introduction, the paper is presented as follows: the second section provides a review of the literature available on the selected topic; the third section describes the data and methodology, while the fourth section discusses the empirical results.

\section{LITERATURE REVIEW}

\subsection{Theoretical Framework}

The literature we reviewed numerates three mechanisms to adjust BOP; namely, the absorption and elasticity approaches (related to Keynesian theory) and the monetary approach. The MABP differs from the absorption and elasticity approaches in that it focuses on the overall BOP, whilst the others focus on the current account of the BOP and neglect the implications of capital movements (Coppin, 1994). 


\subsubsection{Elasticity Approach}

Robinson (1937) introduced the elasticity approach. This approach addresses how a country's exports and imports can be affected by the exchange rate change (trade balance); other variables (including income) can be overlooked. This concept applies the Marshall-Learner restriction. It refers to the sum of the elasticity of demand for imports and exports in absolute terms, which ought to be greater than one for a devaluation to ameliorate BOP (Fleermuys, 2005). This approach ignores the capital account resulting from a surplus or shortage of exports, which results from imports causing a BOP spare or deficit; this has a major effect on the current account to the BOP.

\subsubsection{The Absorption Approach}

Alexander (1952) proposed the absorption approach to emphasise the importance of income change for the adjustment process. The objective of this approach is to demonstrate how the relationship between expenditure and income in nominal and real terms is affected by devaluation. Moreover, it is argued that the increase in inflationary prices is a result of devaluation; this in turn renders the initial effect of the rise in prices ineffective. Consequesntly, this process can be impeded only in case the aggregate demand for goods is lowered by inflation, aided by the influence of an income redistribution, or having the value of existing money balance decreased (Fleermuys, 2005). We can also say that this approach places great emphasis on the current account.

\subsubsection{Monetary Approach to the Balance of Payments (MABP)}

The basis for MABP has been theoretically established by academics, including Frenkel (1971), Mundell (1971), Johnson (1972), and Dornbusch (1973), to name a few. The MABP assumes that BOP is a monetary phenomenon, which can be expressed through the relationship between a country's BOP and its money supply (Umer et al., 2010). Moreover, the prevailing imbalances in the money market affect the overall BOP. Specifically, if the supply of money is more than the demand for money, it creates deficits in BOP, and in the reverse case, it creates a surplus (Howard \& Mamingi, 2002). The MABP model is formulated through the following equations:

$$
\begin{gathered}
M^{d}=F(Y, P, I), \\
M^{s}=(R+D C), \\
M^{d}=M^{s}=M .
\end{gathered}
$$

In Eqs. (1), (2) and (3), $M^{d}$ indicates money demand, $M^{s}$ is money supply, $R$ is the foreign reserves, $D C$ is the domestic credit, $Y$ is the real domestic income, $P$ is the price level, $I$ is the nominal interest rate and $M$ is the money market equilibrium. 
On the one hand, examining the related literature shows that money demand and income $\left(M^{d} / Y>0\right)$ and money demand and price level $\left(M^{d} / P>0\right)$ are positively related. On other hand, money holding and interest rate $\left(M^{d} / I<0\right)$ exhibit a negative relation with each other. The low interest rate, particularly, results in an increase in money demand that is used in investments.

Equations (1), (2) are combined in Eq. 3 to obtain the following reserve flow equation with variables expressed through percentage change:

$$
\Delta R=\Delta[F(Y, P, I)]-\Delta D C .
$$

Equation (4) is identified as the basic equation for MABP; it explains the foreign reserves (BOP) as a shift in the growth of money demand from domestic credit growth, with the money market being in balance at the same time. Similarly, there is inverse relationship between the change in domestic credit and that in international reserves. Therefore, the parameter of $\Delta D$ can be known as an offset parameter whose sign is negative according to the MABP propositions (Dhliwayo, 1996).

\subsection{Empirical Literature}

Literature is rich with empirical studies on the MABP, and most of these studies are built on the "reserve-flow equation". Aghevli and Khan (1977) investigated MABP in a group of developing countries and detected arguments that support MABP. However, Watson (1990) did not record any findings that conformed with what the MABP predicted in Trinidad and Tobago's BOP study during the period of 1965-1985.

In another study, Coppin (1994) examined the validity of the MABP in Barbados; what he found was that the degree of openness of an economy and expansionary fiscal policy had a remarkable significance in specifying BOP. Besides, his arguments were in favour of MABP in the case of Barbados. Dhliwayo (1996) employed the multivariate co-integration and error-correction modelling to test the MABP in Zimbabwe during the period of 1980-1991. The findings confirmed the importance of money in explaining the BOP. What he also identified was a negative relation between domestic credit and the international reserves.

Fleermuys (2005) studied the MABP in Namibia using the Engel-Granger technique for a long-run estimation and quarterly data for the period of 1993-2003. The results showed that Namibia's BOP was not entirely a monetary phenomenon, and that net foreign assets were influenced only by domestic credit and inflation. Another study conducted by Adamu and Itsede (2010) tested the MABP in the West Africa Monetary Zone (WAMZ) countries, using panel data estimation techniques for the period of 1975-2008. The results suggested a significant negative relation between domestic credit and net foreign assets. The conclusion was that strict regulations on domestic credit creation were required to maintain stability on BOP in WAMZ.

By utilising the monetary approach, the co-integration test and error correction model, Umer et al. (2010) investigated the BOP of Pakistan from 1980 to 2008. The 
results denoted that monetary variables did not have a vast part in explaining the Pakistanian BOP. It concluded that the monetary instruments were not the only options for authorities to adjust the BOP imbalance. Similarly, Danjuma (2013) also found that BOP was not a purely monetary phenomenon in Nigeria, although the study used a different model, the Johnson Cointegration and Vector Error Correction Model, to assess the period between 1986 and 2010. However, it was noted that domestic credit creation should be given special attention by the authorities to improve Nigeria's BOP.

Al-Basheer and Malawi (2016) employed the Autoregressive Distributed Lag (ARDL) technique and annual data covering the period of 1980-2012 to check the impact of monetary policy on Jordanian foreign reserves through the MABP. The findings revealed a relationship between monetary variables and foreign reserves in the long run. Also, the parameters of the long run were statistically significant and consistent with the MABP propositions. Focusing on Ghana, Senyefia et al. (2019) examined the MABP between January 2006 and February 2018 using the ARDL technique. The empirical results denoted that the BOP in Ghana was a purely monetary phenomenon. Hence, the authorities could rely on prudent monetary policies to correct the country's BOP.

The reviewed studies used different econometric methodologies and various independent variables. Most of studies concluded that the BOP was a purely monetary phenomenon, while some had mixed results. Moreover, we noticed that there are few cross-country studies compared to single-country studies. Another issue is that the techniques used in the previous cross-country studies are the traditional panel data techniques that do not consider CSD and slope heterogeneity. Therefore, this paper attempts to investigate the MABP in more developing countries as five selected MENA countries. This will be achieved using secondgeneration panel data techniques that consider the CSD and slope heterogeneity providing more precise and unbiased results.

\section{DATA AND METHODOLOGY}

\subsection{Data and Model Specification}

The objective of this study is to check if monetary variables, especially domestic credit, play a significant role in determining the BOP in the context of the MABP in the panel of five selected MENA countries (Jordan, Egypt, Algeria, Morocco, Tunisia) during the period of 1980-2019. Based on the reviewed literature, the model we have formulated is the following:

$$
N F A_{i t}=\beta_{0 i}+\beta_{1} G D P_{i t}+\beta_{2} D C_{i t}+\beta_{3} C P I_{i t}+\beta_{4} E X_{i t}+\beta_{5} I N T_{i t}+\epsilon_{i t} .
$$

In Eq. (5), NFA represents the net foreign assets (which include the foreign reserves and gold), GDP is the gross domestic product as a proxy for the domestic income level, DC is domestic credit (which is the inclusive net claims on the public sector and net claims on the private sector), CPI is the consumer price index (2010 $=100$ ) that represents the price level, EX is the official exchange rate, and INT is the discount rate (which represents the interest rate). The dataset was obtained from 
the World Development Indicators, the IMF's International Financial Statistics database, and Central Bank statistical bulletins. The variables are transformed into natural logarithms except for DC due to negative values. Hence, the following method is employed to modify this variable:

$$
y=\ln \left(x+\sqrt{x^{2}+1}\right) .
$$

This transformation maintains the sign of $x$, the values of $x$ range from a linear scale at small absolute values to a logarithmic scale at large values (Busse \& Hefeker, 2007).

\subsection{Econometric Methodology}

The traditional methods of panel data analysis assumed cross-sectional independence, whilst Pesaran (2004) contends that CSD is considered necessary for macro panel data analysis where $N$ is short and $T$ is large. Therefore, in recent years, new techniques have been developed to deal with this problem.

\subsubsection{Cross-Sectional Dependence (CSD)}

In panel data analysis, the obtained estimators can be biased and inconsistent if CSD is not controlled (Ho Deyos \& Sarafidis, 2006). Thus, the detection of CSD in panel data analysis is necessary. Breusch and Pagan (1980) suggested utilising Lagrange multiplier statistic (LM) for testing the CSD, with $N$ being fixed and $T \rightarrow \infty$. This tests is based on the following equation:

$$
y_{i t}=\alpha_{i}+\beta_{i} X_{i t}+\epsilon_{i t},
$$

where $i$ and $t$ represent cross-section and time dimensions, respectively. The next formula represents the LM statistic:

$$
L M=T \sum_{i=1}^{N-1} \sum_{j=i+1}^{N} \hat{\rho}_{i j}^{2},
$$

where $\hat{\rho}_{i j}$ is the sample estimate of the pair-wise correlation of the residuals of Eq. (7). CSD is tested for the null hypothesis of $H_{0}: \operatorname{Cov}\left(\epsilon_{i t}, \epsilon_{j t}\right)=0$, which presupposes the absence of CSD. The alternative hypothesis $H_{1}: \operatorname{Cov}\left(\epsilon_{i t}, \epsilon_{j t}\right) \neq 0$ indicates the existence of CSD.

To deal with the bias of a large $N$ in the LM test, Pesaran (2004) proposes using the $C D_{L M}$ statistic specified by:

$$
C D_{L M}=\sqrt{\frac{2 T}{N(N-1)}} \sum_{i=1}^{N-1} \sum_{j=i+1}^{N} \hat{\rho}_{i j} .
$$

Pesaran et al. (2008) provided a modulation to the LM test for $N \rightarrow \infty$ and $T \rightarrow \infty$ due to the lack of power situation of $C D_{L M}$ test as follows: 


$$
L M_{a d j}=\sqrt{\frac{2}{N(N-1)} \sum_{i=1}^{N-1} \sum_{j=i+1}^{N} \frac{(T-k) \hat{\rho}_{i j}^{2}-\mu_{T i j}}{v_{T i j}}},
$$

where $\mu_{T i j}$ and $v_{T i j}$ represent the exact mean and variance of $(T-k) \hat{\rho}_{i j}^{2}$, respectively.

\subsubsection{Slope Heterogeneity}

Swamy (1970) suggested a test of slope heterogeneity based on the dispersion of regression coefficients of the singular estimation from a pooled estimator. The following formula defines Swamy's test statistic:

$$
\tilde{S}=\sum_{i=1}^{N}\left(\hat{\beta}_{i}-\tilde{\beta}_{W F E}\right)^{\prime} \frac{X_{i}^{\prime} M_{\tau} X_{i}}{\tilde{\sigma}_{i}^{2}}\left(\hat{\beta}_{i}-\tilde{\beta}_{W F E}\right),
$$

where $\hat{\beta}_{i}$ and $\tilde{\beta}_{W F E}$ indicate the OLS estimators of every country $i$ and the weighted fixed effect (WFE) pooled estimator, respectively, while $M_{\tau}$ is the identity matrix. Pesaran and Yamagata (2008) developed Swamy's test statistic, which is presented as follows:

$$
\begin{gathered}
\tilde{\Delta}=\sqrt{N}\left(\frac{N^{-1} \tilde{S}-k}{\sqrt{2 k}}\right), \\
\tilde{\Delta}_{a d j}=\sqrt{N}\left(\frac{N^{-1} \tilde{S}-E\left(\tilde{Z}_{i t}\right)}{\sqrt{\operatorname{var}\left(\tilde{Z}_{i t}\right)}}\right) .
\end{gathered}
$$

Equations (12) and (13) represent the standardized dispersion statistic $\tilde{\Delta}$ and the biased-adjusted one $\tilde{\Delta}_{a d j}$, where $E\left(\tilde{Z}_{i t}\right)=k$ and $\operatorname{var}\left(\tilde{Z}_{i t}\right)=\frac{2 k(T-k-1)}{T+1}$, and $k$ is the number of explanatory variables. The null and alternative hypotheses to the test slope heterogeneity are defined as follows:

- $H_{0}: \beta_{i}=\beta$,

- $H_{1}: \beta_{i} \neq \beta$.

$H_{0}$ states the homogeneity of the slope coefficients in the panel data model.

\subsubsection{Panel Unit Root Test}

Pesaran (2007) proposed a unit root test of the second-generation that is made robust in the presence of CSD. This test aims at reinforcing the augmented DickeyFuller (ADF) regressions using cross-section averages of lagged levels and first differences of the individual series. The cross-sectional ADF (CADF) regression is given by:

$$
\Delta y_{i t}=a_{i}+b_{i} y_{i, t-1}+c_{i} \bar{y}_{t-1}+d_{i} \Delta \bar{y}_{t}+\epsilon_{i t}
$$


where $\bar{y}_{t-1}=\frac{1}{N} \sum_{i=1}^{N} y_{i, t-1}$ and $\Delta \bar{y}_{t}=\frac{1}{N} \sum_{i=1}^{N} \Delta y_{i, t}$.

The following formula represents Pesaran's statistic (CIPS), which is calculated from the average of the $t$ statistics for each cross-section unit (CADFi) in the panel data.

$$
C I P S=\frac{1}{N} \sum_{i=1}^{N} C A D F_{i}
$$

$H_{0}$ is rejected for the presence of unit root if the computed CIPS statistic is larger than the critical values.

\subsubsection{Second-Generation Co-integration Test}

To check the presence of a long-run relationship among variables, Westerlund (2007) developed the second-generation panel co-integration test that is effective in dealing withing CSD. This test examines $H_{0}$ of no co-integration by finding whether the error correction for individual countries as well as the whole panel is equal to zero. The error correction is given as:

$$
\Delta y_{i, t}=\delta_{i}^{\prime} d_{t}+\alpha_{i}\left(y_{i, t-1}-\beta_{i}^{\prime} x_{i, t-1}\right)+\sum_{j=1}^{p_{i}} \alpha_{i j} \Delta y_{i, t-j}+\sum_{j=-q_{i}}^{p_{i}} \gamma_{i j} \Delta x_{i, t-j}+\epsilon_{i t},
$$

where $\alpha_{i}$ is the error correction, which denotes the term of adjustment speed.

$H_{0}$ of no co-integration is examined using the group-mean tests (based on $G_{\tau}$ and $G_{\alpha}$ statistics) and the panel tests (based on $P_{\tau}$ and $P_{\alpha}$ statistics), which can be provided through the estimators of Eq. (16). These tests are based on structural dynamics; all variables should be stationary at the first difference (I(1)) (Hicham, 2020).

$$
\begin{gathered}
G_{\tau}=\frac{1}{N} \sum_{i=1}^{N} \frac{\alpha_{i}}{\operatorname{Se}\left(\alpha_{i}\right)}, \\
G_{\alpha}=\frac{1}{N} \sum_{i=1}^{N} \frac{T \alpha_{i}}{\alpha_{i}^{\prime}}, \\
P_{\tau}=\frac{\alpha_{i}}{\operatorname{Se}\left(\alpha_{i}\right)}, \\
P_{\alpha}=T \alpha_{i} .
\end{gathered}
$$

The $G_{\tau}$ and $G_{\alpha}$ statistics are employed for revealing whether cointegration manifests itself in at least one cross-sectional country. The $P_{\tau}$ and $P_{\alpha}$ statistics detect if cointegration appears in the whole panel (Le, 2020). 


\subsubsection{Long-Run Relationship Estimate}

In order to estimate the long-run relationship, this paper uses the CCEMG estimator that Pesaran (2006) suggested, and the AMG estimator that Eberhardt and Bond (2009) and Eberhardt and Teal (2011) presented. Both estimators are effective when dealing with parameter heterogeneity and CSD. The CCEMG estimator is obtained through the next equation estimators:

$$
y_{i t}=\alpha_{i}+\beta_{i} x_{i t}+\gamma_{i} \bar{y}_{i t}+\delta_{i} \bar{x}_{i t}+\varphi_{i} f_{t}+\epsilon_{i t},
$$

where $\beta_{i}$ indicates the individual-specific slope, and $f_{t}$ represents the unobserved common effects factor. The CCEMG estimator is obtained by calculating the simple average of the individual CCE estimators as shown in the following equation:

$$
\hat{\beta}_{C C E M G}=\frac{1}{N} \sum_{i=1}^{N} \hat{\beta}_{i},
$$

where $\hat{\beta}_{i}$ represents the estimate of parameters in Eq. (21).

The AMG estimator developed by Eberhardt and Bond (2009) and Eberhardt and Teal (2011) is provided through the following regressions:

$$
\begin{gathered}
\Delta y_{i t}=\beta \Delta x_{i t}+\sum_{t=2}^{T} \theta_{t} \Delta D_{t}+\epsilon_{i t}, \\
y_{i t}=\alpha_{i}+\beta_{i} x_{i t}+\varphi_{i} t+d_{i} \dot{\mu}_{t}+\epsilon_{i t} .
\end{gathered}
$$

Equation (23) is a standard OLS regression in first differences with $T-1$ year dummies, through which the time dummy parameter $\left(\dot{\mu}_{t}\right)$ is obtained. In Eq. (24), $\dot{\mu}_{t}$ and the linear trend are included in the $N$ standard individual regressions. AMG estimator is calculated by employing the same procedure used for the CCEMG.

$$
\hat{\beta}_{A M G}=\frac{1}{N} \sum_{i=1}^{N} \hat{\beta}_{i},
$$

where $\hat{\beta}_{i}$ is the estimate of coefficients in Eq. (24).

The essential difference among the CCEMG and AMG estimators is in the technique used to deal with CSD. The CCEMG estimator adds linear combinations of cross-sectional averages of the observed common effect to deal with CSD. On the other hand, the AMG estimator solves this problem by including the coefficient of the common dynamic effect.

\section{EMPIRICAL RESULTS}

The descriptive statistics of variables, which include mean, maximum (Max), minimum (Min) and standard deviation (SD), are denoted in Table 1. The standard deviation values of net foreign assets, GDP, domestic credit, consumer price, and interest rate indicate that there are not vast variations among the data over time in 
each distribution. However, the standard deviation value of the exchange rate denotes the presence of a range of fluctuations of exchange rate data.

Table 1. Descriptive Statistics of Variables

\begin{tabular}{|l|l|l|l|l|}
\hline \multicolumn{1}{|c|}{ Variable } & \multicolumn{1}{c|}{ Mean } & \multicolumn{1}{c|}{ Min } & \multicolumn{1}{c|}{ Max } & \multicolumn{1}{c|}{ SD } \\
\hline LNFA & 8.713355 & 5.582 & 12.213 & 1.501844 \\
\hline LGDP & 10.86891 & 8.948 & 12.619 & 0.9313825 \\
\hline LDC & 10.19493 & -10.679 & 13.379 & 3.702937 \\
\hline LCPI & 4.013625 & 1.391 & 5.665 & 0.8230418 \\
\hline LEX & 1.50857 & -1.211 & 4.782 & 1.512988 \\
\hline LINT & 1.863785 & 0.811 & 2.996 & 0.5049272 \\
\hline
\end{tabular}

Note: The authors' computation is based on STATA 15 (2021).

Table 2 represents the correlation matrix. This matrix denotes a correlation value of 0.72 between the exchange rate and the GDP, which indicates a strong relationship between these two variables and thus may result in a multicollinearity problem in the model. Therefore, multicollinearity is tested using the values of the variance inflation factor (VIF). A VIF value that exceeds 5 indicates a multicollinearity problem (James et al., 2013).

Table 2. The Matrix of Variable Correlation

\begin{tabular}{|c|c|c|c|c|c|c|}
\hline Variable & LNFA & LGDP & LDC & LCPI & LEX & LINT \\
\hline LNFA & 1.0000 & & & & & \\
\hline LGDP & 0.7612 & 1.0000 & & & & \\
\hline LDC & -0.1676 & 0.0532 & 1.0000 & & & \\
\hline LCPI & 0.5256 & 0.2035 & -0.0430 & 1.0000 & & \\
\hline LEX & 0.5829 & 0.7219 & -0.2018 & 0.3685 & 1.0000 & \\
\hline LINT & -0.3453 & -0.0224 & 0.1384 & -0.2720 & -0.2028 & 1.0000 \\
\hline
\end{tabular}

Note: The authors' computation is based on STATA 15 (2021).

In Table 3, the results denote that VIF values are less than 5. Thus, multicollinearity is likely not a problem.

Table 3. The VIF Values

\begin{tabular}{|l|l|l|}
\hline \multicolumn{1}{|c|}{ Variable } & \multicolumn{1}{c|}{ VIF } & \multicolumn{1}{c|}{ 1/VIF } \\
\hline LGDP & 2.36 & 0.42 \\
\hline LDC & 1.15 & 0.87 \\
\hline LCPI & 1.23 & 0.82 \\
\hline LEX & 2.74 & 0.36 \\
\hline LINT & 1.13 & 0.88 \\
\hline Mean VIF & 1.72 & \\
\hline
\end{tabular}

Note: The authors' computation is based on STATA 15 (2021). 
According to the findings of CSD and slope homogeneity tests, which are displayed in Table 4, the results of the Bias Adjusted LM Test denote that $H_{0}$ of no CSD was rejected for all variables and the model as a whole at $1 \%$ level. Furthermore, $H_{0}$ of parameters homogeneity is rejected at $1 \%$ level after slope homogeneity tests.

Table 4. The results of CSD and Slope Homogeneity Tests

\begin{tabular}{|c|c|c|c|c|c|c|c|}
\hline Test & LNFA & LGDP & LDC & LCPI & LEX & LINT & Model \\
\hline LM & $\begin{array}{l}84.19 \\
(0.0000)\end{array}$ & $\begin{array}{l}36.68 \\
(0.0001)\end{array}$ & $\begin{array}{l}70.3 \\
(0.0000)\end{array}$ & $\begin{array}{l}225 \\
(0.0000)\end{array}$ & $\begin{array}{l}86.86 \\
(0.0000)\end{array}$ & $\begin{array}{l}122.8 \\
(0.0000)\end{array}$ & $\begin{array}{l}15.9 \\
(0.1027)\end{array}$ \\
\hline CD LM & $\begin{array}{l}6.555 \\
(0.0000)\end{array}$ & $\begin{array}{l}3.022 \\
(0.0025)\end{array}$ & $\begin{array}{l}1.273 \\
(0.2028)\end{array}$ & $\begin{array}{l}14.85 \\
(0.0000)\end{array}$ & $\begin{array}{l}5.622 \\
(0.0000)\end{array}$ & $\begin{array}{l}10.73 \\
(0.0000)\end{array}$ & $\begin{array}{l}1.942 \\
(0.0521)\end{array}$ \\
\hline LM adj & $\begin{array}{l}57.98 \\
(0.0000) \\
\end{array}$ & $\begin{array}{l}20.59 \\
(0.0000)\end{array}$ & $\begin{array}{l}47.04 \\
(0.0000)\end{array}$ & $\begin{array}{l}168.8 \\
(0.0000)\end{array}$ & $\begin{array}{l}60.08 \\
(0.0000)\end{array}$ & $\begin{array}{l}88.34 \\
(0.0000)\end{array}$ & $\begin{array}{l}3.125 \\
(0.0018) \\
\end{array}$ \\
\hline$\tilde{\Delta}$ & & & & & & & $\begin{array}{l}12.571 \\
(0.0000) \\
\end{array}$ \\
\hline$\tilde{\Delta}_{a d j}$ & & & & & & & $\begin{array}{l}13.841 \\
(0.0000) \\
\end{array}$ \\
\hline
\end{tabular}

Probability values are displayed between parentheses.

Note: The authors' computation is based on STATA 15 (2021).

Table 5. Panel Unit Root Test Results

\begin{tabular}{|l|c|c|c|}
\hline \multicolumn{1}{|c|}{ Variable } & Level & First difference & Results \\
\hline LNFA & -2.454 & $-5.333 * * *$ & $\mathrm{I}(1)$ \\
\hline LGDP & -2.046 & $-4.403 * * *$ & $\mathrm{I}(1)$ \\
\hline LDC & -2.689 & $-3.535 * * *$ & $\mathrm{I}(1)$ \\
\hline LCPI & -1.890 & $-3.380 * * *$ & $\mathrm{I}(1)$ \\
\hline LEX & -1.747 & $-3.841 * * *$ & $\mathrm{I}(1)$ \\
\hline LINT & -2.574 & $-5.245 * * *$ & $\mathrm{I}(1)$ \\
\hline
\end{tabular}

*** denotes the rejection of $H_{0}$ at $1 \%$ significance level.

Note: The authors' computation is based on STATA 15 (2021).

After checking the existence of CSD and slope heterogeneity, the stationarity of variables is examined by employing the second-generation panel unit root test CIPS provided by Pesaran (2007). The findings of Table 5 denote that all variables are nonstationary in level while they are stationary at the first difference (I(1)). Hence, no variables are available in the panel data except I(1).

To reveal the possibility of a long-run relationship among the variables and take into account the formerly obtained results at the same time, the authors applied the co-integration test developed by Westerlund (2007). According to the findings of Table 6 , the robust $p$-values of $G_{\alpha}$ and $P_{\alpha}$ statistics are statistically significant at $10 \%$ level. Thus, $H_{0}$ is rejected, and we confirm the co-integration relationship among net foreign assets, GDP, domestic credit, consumer price, exchange rate and interest rate. 
Table 6. Co-integration Test Results of Westerlund (2007)

\begin{tabular}{|l|c|c|c|c|}
\hline Statistic & Value & $Z$-value & $P$-value & Robust $P$-value \\
\hline$G_{t}$ & -2.340 & -0.312 & 0.378 & 0.158 \\
\hline$G_{a}$ & $-7.112^{*}$ & 1.343 & 0.910 & 0.083 \\
\hline$P_{t}$ & -4.307 & -0.082 & 0.467 & 0.225 \\
\hline$P_{a}$ & $-6.556^{*}$ & 0.415 & 0.661 & 0.055 \\
\hline
\end{tabular}

* denotes the rejection of $H_{0}$ at $10 \%$ significance level.

Note: The authors' computation is based on STATA 15 (2021).

After confirming the cointegration relationship, the long-run parameters are estimated by employing the CCEMG and AMG estimators, which are strong in the presence of CSD and slope heterogeneity.

Table 7. CCEMG and AMG Estimation Results

\begin{tabular}{|l|l|l|}
\hline Variable & CCEMG & AMG \\
\hline LGDP & $\begin{array}{l}2.040 * * * \\
(2.75)\end{array}$ & $\begin{array}{l}1.193 * * * \\
(4.28)\end{array}$ \\
\hline LDC & $\begin{array}{l}-0.679 * * \\
(-2.16)\end{array}$ & $\begin{array}{l}-0.719 * \\
(-1.89)\end{array}$ \\
\hline LCPI & $\begin{array}{l}2.287 * * * \\
(2.81)\end{array}$ & $\begin{array}{l}1.781 * * * \\
(2.83)\end{array}$ \\
\hline LEX & $\begin{array}{l}-0.810 \\
(-1.40)\end{array}$ & $\begin{array}{l}-0.957 * * \\
(-2.17)\end{array}$ \\
\hline LINT & $\begin{array}{l}-0.0543 \\
(-0.18)\end{array}$ & $\begin{array}{l}-0.458 * * * \\
(-3.16)\end{array}$ \\
\hline C & $\begin{array}{l}-7.545 \\
(-0.94)\end{array}$ & $\begin{array}{l}-2.562 \\
(-0.58)\end{array}$ \\
\hline
\end{tabular}

$* * *, * *$, and $*$ denote the rejection of $H_{0}$ at $1 \%, 5 \%$ and $10 \%$ significance level, respectively. $t$ statistics are displayed between parentheses.

Note: The authors' computation is based on STATA 15 (2021).

According to the panel estimation results showed in Table 7, the AMG estimator strongly supports the propositions of MABP, with a negative and significant domestic credit coefficient. Specifically, increasing GDP and consumer price by $1 \%$ improves the net foreign assets by $1.19 \%$ and $1.78 \%$, respectively. Concerning the domestic credit, exchange rate and interest rate increase by $1 \%$, and the net foreign assets drop by $0.72 \%, 0.96 \%$ and $0.46 \%$, respectively. As for the CCEMG estimator results, the GDP, domestic credit and consumer price coefficients are statistically significant and compatible with the MABP predictions, while the interest rate and the exchange rate do not play any role in determining net foreign assets.

Table 8 shows the country-specific results of the AMG estimator. Accordingly, the AMG estimator results strongly supported the MABP propositions in Jordan, Morocco, and to a lesser extent, Algeria, and Egypt. 
Table 8. Country-Specific Results of the AMG Estimator

\begin{tabular}{|l|l|l|l|l|l|}
\hline \multirow{2}{*}{ Country } & \multicolumn{5}{|c|}{ AMG estimator } \\
\cline { 2 - 6 } & \multicolumn{1}{|c|}{ LGDP } & \multicolumn{1}{c|}{ LDC } & \multicolumn{1}{c|}{ LCP } & \multicolumn{1}{c|}{ LEXCH } & \multicolumn{1}{c|}{ LINTD } \\
\hline \multirow{2}{*}{ Algeria } & $\begin{array}{l}1.071^{*} \\
(1.95)\end{array}$ & $\begin{array}{l}-0.016^{* *} \\
(-2.22)\end{array}$ & $\begin{array}{l}1.105^{* *} \\
(2.24)\end{array}$ & $\begin{array}{l}-0.534 \\
(-1.59)\end{array}$ & $\begin{array}{l}-0.929 * * * \\
(-7.02)\end{array}$ \\
\hline \multirow{2}{*}{ Egypt } & $\begin{array}{l}0.962 \\
(0.93)\end{array}$ & $\begin{array}{l}-1.474 * * * \\
(-4.60)\end{array}$ & $\begin{array}{l}1.563^{* * *} \\
(5.39)\end{array}$ & $\begin{array}{l}-0.618^{* * *} \\
(-2.03)\end{array}$ & $\begin{array}{l}-0.209 \\
(-0.78)\end{array}$ \\
\hline Jordan & $\begin{array}{l}1.756^{* * *} \\
(2.73)\end{array}$ & $\begin{array}{l}-0.882^{* * *} \\
(-3.93)\end{array}$ & $\begin{array}{l}2.310^{* * *} \\
(3.25)\end{array}$ & $\begin{array}{l}-2.055^{* * *} \\
(-3.41)\end{array}$ & $\begin{array}{l}-0.302 * * \\
(-2.10)\end{array}$ \\
\hline Morocco & $\begin{array}{l}1.786^{* * *} \\
(3.15)\end{array}$ & $\begin{array}{l}-1.330^{* * *} \\
(-5.05)\end{array}$ & $\begin{array}{l}3.723 * * * \\
(5.65)\end{array}$ & $\begin{array}{l}-1.601 * * * \\
(-2.63)\end{array}$ & $\begin{array}{l}-0.579 * * * \\
(-2.74)\end{array}$ \\
\hline Tunisia & $\begin{array}{l}0.374 \\
(0.41)\end{array}$ & $\begin{array}{l}0.148 \\
(0.50)\end{array}$ & $\begin{array}{l}0.572 \\
(1.21)\end{array}$ & $\begin{array}{l}-0.093 \\
(-0.57)\end{array}$ & $\begin{array}{l}-0.381 \\
(-1.40)\end{array}$ \\
\hline
\end{tabular}

$* * *, * *$, and $*$ denote the rejection of $H_{0}$ at $1 \%, 5 \%$ and $10 \%$ significance level, respectively. $t$ statistics are displayed between parentheses.

Note: The authors' computation is based on STATA 15 (2021).

As for Tunisia, the presented results do not conform with what MABP predicted. Specifically, in Algeria, the results show that a $1 \%$ increase in domestic credit can lead to a slight decrease in net foreign assets by $0.016 \%$. The GDP, consumer price and interest rate have a significant impact on net foreign assets. However, the exchange rate was found to have no significance. As for Egypt, a $1 \%$ increase in the domestic credit causes the decline of net foreign assets by $1.474 \%$. GDP and interest rate are insignificant in determining the net foreign assets. The remaining variables have a highly significant impact on net foreign assets. In Jordan and Morocco, a $1 \%$ increase in domestic credit leads to a decrease in net foreign assets by $0.882 \%$ and $1.33 \%$, respectively. Also, the other variables play an important role in determining net foreign assets in these countries. For Tunisia, the results indicate that all coefficients of variables are statistically insignificant. Therefore, we can say that these variables, including domestic credit, do not play any role in determining net foreign assets in Tunisia.

\section{CONCLUSION AND POLICY RECOMMENDATIONS}

This study investigated the long-run relationship between domestic credit and net foreign assets through the MABP in five selected MENA countries (Jordan, Egypt, Algeria, Morocco, Tunisia) for the period extending from 1980 to 2019. After exploring CSD and the heterogeneity of the parameters in panel data, we found that all variables were stationary at the first difference after using the panel unit root test of the second-generation (CIPS). Westerlund co-integration test findings also gave evidence for the presence of a long-run relationship among net foreign assets, GDP, domestic credit, consumer price, exchange rate and interest rate. According to panel results, the CCEMG and AMG estimators provided slightly different results. The AMG estimator indicatet that all variables had a highly significant impact on net foreign assets, and signs of their coefficients were consistent with MABP prediction. 
On the other hand, the CCEMG estimator results showed that only GDP, domestic credit and consumer price coefficients were statistically significant and consistent with MABP. However, both estimators confirmed that domestic credit played an influential role in determining BOP in the long run. The country-specific results for the AMG estimator strongly supported the MABP in Jordan and Morocco, whilst the BOP was not a purely monetary phenomenon by AMG estimator in Algeria and Egypt. However, the significant and negative relation between domestic credit and net foreign assets was established in Algeria, Egypt, Jordan, and Morocco, although in Algeria, the coefficient of domestic credit had little effect on the net foreign assets. As for Tunisia, the results did not show any evidence regarding the MABP in the long run.

The main policy implications of the present results hint that the increase in domestic credit leads to a continuous loss of net foreign assets in Egypt, Jordan, Morocco, and Algeria. Thus, domestic credit can be both a cause and a cure for the BOP deficit. In these countries, monetary authorities should formulate the appropriate monetary policies to control the creation of domestic credit as a mechanism to maintain the stability of the country's BOP. The policymakers of these countries must also target a prudent fiscal policy to finance the budget deficit out of rationalization of government expenditure and the efficient collection of tax revenues, instead of resorting to borrowing from the central bank. It is because the latter causes an increase in domestic credit creation. An additional implication for policymakers concerns the requirement for other mechanisms to adjust the imbalance. Therefore, the policymakers should concentrate on other policy instruments to correct the BOP deficits rather than focusing on monetary tools, especially in Tunisia, where the findings showed that BOP was not a monetary phenomenon.

\section{ACKNOWLEDGEMENT}

The research has been supported by the General Directorate of Scientific Research and Technological Development (DGRSDT), Algeria.

\section{REFERENCES}

Adamu, P. A., \& Itsede, O. C. (2010). Balance of payments adjustment: The West African monetary zone experience. Journal of Monetary and Economic Integration, 10(2), 100-116.

Aghevli, B. B., \& Khan, M. S. (1977). The monetary approach to balance of payments determination: an empirical test. The Monetary Approach to the Balance of Payments, 275-290. https://doi.org/10.5089/9781557752772.071

Akpansung, A. O. (1998). Applicability of monetary approach to Nigeria's balance of payments, 1960-1995. Unpublished M. Sc (Economics) Thesis, University of Calabar, Nigeria.

Al-Basheer, A. A.-H., \& Malawi, A. I. (2016). The Impact of Monetary Policy on Foreign Reserves: MABP Approach. Jordan Journal of Economic Sciences, 406(3655), 1-24.

Alexander, S. S. (1952). Effects of a Devaluation on a Trade Balance. Staff Papers-International Monetary Fund, 2(2), 263-278. https://doi.org/10.2307/3866218

Boateng, C., \& Ayentimi, D. T. (2013). An empirical analysis of balance of payment in Ghana using the monetary approach. European Journal of Business and Management, 5(8).

Breusch, T. S., \& Pagan, A. R. (1980). The Lagrange multiplier test and its applications to model specification in econometrics. The Review of Economic Studies, 47(1), 239-253. https://doi.org/10.2307/2297111 
Busse, M., \& Hefeker, C. (2007). Political risk, institutions and foreign direct investment. European Journal of Political Economy, 23(2), 397-415. https://doi.org/10.1016/j.ejpoleco.2006.02.003

Coppin, A. (1994). The determinants of international reserves in Barbados: a test of the monetarist approach. Social and Economic Studies, 43(2), 75-89.

Danjuma, B. F. (2013). An empirical analysis of the balance of payments as a monetary phenomenon: Nigeria's experience. Journal of Emerging Issues in Economics, Finance and Banking, 1(2).

Dhliwayo, R. (1996). Balance of payments as a monetary phenomenon: an econometric study of Zimbabwe's experience. African Economic Research Consortium, Nairobi, KE.

Dornbusch, R. (1973). Devaluation, money, and nontraded goods. The American Economic Review, 63(5), 871-880.

Eberhardt, M., \& Bond, S. (2009). Cross-section dependence in nonstationary panel models: A novel estimator. MPRA Paper 17692, University Library of Munich.

Eberhardt, M., \& Teal, F. (2011). Econometrics for grumblers: a new look at the literature on crosscountry growth empirics. Journal of Economic Surveys, 25(1), 109-155. https://doi.org/10.1111/j.1467-6419.2010.00624.x

Fleermuys, F. N. (2005). The balance of payments as a monetary phenomenon: An econometric study of Namibia (Issue 72). Ministry of Environment and Tourism.

Frenkel, J. A. (1971). A theory of money trade and the balance of payments in a model of accumulation. Journal of International Economics, 1(2), 159-187. https://doi.org/10.1016/00221996(71)90054-7

Hicham, A. (2020). Government Expenditure and Economic Growth Nexus in Mena Countries: Frequency Domain Spectral Causality Analysis. Economics and Business, 34(1), 60-77. https://doi.org/10.2478/eb-2020-0005

Ho Deyos, R. E., \& Sarafidis, V. (2006). Testing for cross-sectional dependence in panel-data models. The Stata Journal, 6(4), 482-496. https://doi.org/10.1177/1536867X0600600403

Howard, M., \& Mamingi, N. (2002). The monetary approach to the balance of payments: An application to Barbados. The Singapore Economic Review, 47(02), 213-228. https://doi.org/10.1142/S0217590802000511

James, G., Witten, D., Hastie, T., \& Tibshirani, R. (2013). An introduction to statistical learning. Springer. https://doi.org/10.1007/978-1-4614-7138-7

Johnson, H. G. (1972). The monetary approach to balance-of-payments theory. Journal of Financial and Quantitative Analysis, 7(2), 1555-1572. https://doi.org/10.2307/2329935

Le, H. P. (2020). The energy-growth nexus revisited: the role of financial development, institutions, government expenditure and trade openness. Heliyon, 6(7), e04369. https://doi.org/10.1016/j.heliyon.2020.e04369

Mundell, R. A. (1971). Monetary Theory: Inflation, Interest, and Growth in the World Economy (Issue 332 MUN).

Paun, C., Mustetescu, R., \& Munteanu, C. (2013). The Monetary Approach of the Balance Of Payments: Empirical Evidences From Emerging Markets. Economic Computation \& Economic Cybernetics Studies \& Research, 47(3).

Pesaran, M. H. (2004). General diagnostic tests for cross-sectional dependence in panels. Empirical Economics, Cambridge Working Papers in Economics, 1-38. https://doi.org/10.17863/CAM.5113

Pesaran, M. H. (2006). Estimation and inference in large heterogeneous panels with a multifactor error structure. Econometrica, 74(4), 967-1012. https://doi.org/10.1111/j.1468$\underline{0262.2006 .00692 . x}$

Pesaran, M. H. (2007). A simple panel unit root test in the presence of cross-section dependence. Journal of Applied Econometrics, 22(2), 265-312. https://doi.org/10.1002/jae.951

Pesaran, M. H., Ullah, A., \& Yamagata, T. (2008). A bias-adjusted LM test of error cross-section independence. The Econometrics Journal, 11(1), 105-127. https://doi.org/10.1111/j.1368423X.2007.00227.x

Pesaran, M. H., \& Yamagata, T. (2008). Testing slope homogeneity in large panels. Journal of Econometrics, 142(1), 50-93. https://doi.org/10.1016/j.jeconom.2007.05.010

Robinson, J. (1937). Introduction to the Theory of Employment. Macmillan and Co. Ltd, London. 
Salam, M. A. (1995). The balance of payments as a monetary phenomenon: an econometric study of India's experience. Indian Economic Journal, 42(3), 70.

Senyefia, B.-A., Oduro-Okyireh, T., \& Osei-Asibey, E. (2019). The Balance Of Payments As A Monetary Phenomenon: An Econometric Study Of Ghana's Experience. International Journal of Economics, Commerce and Management, 7(2), 42-52.

Swamy, P. A. V. B. (1970). Efficient inference in a random coefficient regression model. Econometrica: Journal of the Econometric Society, 38(2), 311-323. https://doi.org/10.2307/1913012

Umer, M., Muhammad, S. D., Abro, A. A., Sheikh, Q. A., \& Ghazali, A. (2010). The balance of payments as a monetary phenomenon: Econometric Evidence from Pakistan. International Research Journal of Finance and Economics, 38(5), 123-154.

Watson, P. K. (1990). Modelling The Balance Of Payments Of Trinidad \\& Tobago 1965-1985: A Policy Making Perspective. Social and Economic Studies, 39(1), 51-70.

Westerlund, J. (2007). Testing for error correction in panel data. Oxford Bulletin of Economics and Statistics, 69(6), 709-748. https://doi.org/10.1111/j.1468-0084.2007.00477.x

\section{AUTHORS' SHORT BIOGRAPHIES}

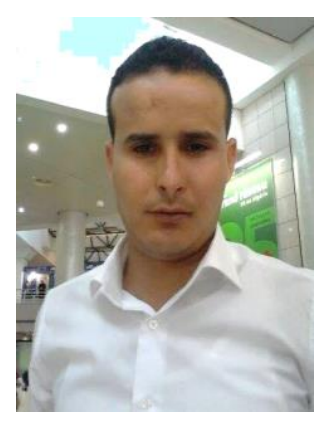

Azeddine Ghilous received the State Engineer degree in applied statistics from the National Planning and Statistical Institute in Algeria in 2007 and the Master degree in quantitative economics from M'sila university in Algeria in 2018. He started pursuing for a $\mathrm{PhD}$ degree in quantitative economics at the Farhat Abbas Setif University in Algeria in November 2018. His research focuses on econometric studies in macroeconomics.

E-mail: azeddine.ghilousse@ univ-setif.dz

ORCID iD: https://orcid.org/0000-0003-1212-6543

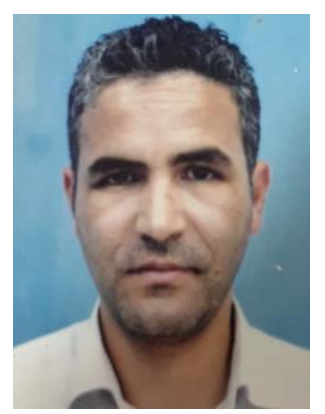

Adel Ziet received a Bachelor degree in economics from the Farhat Abbas Setif University in Algeria in 1995, an MA-LEVEL degree in economics in 2000, and the $\mathrm{PhD}$ degree in economics in 2017. The author has been a Lecturer at Farhat Abbas University Setif-Algeria since 2017. His research focuses on macroeconomics and economic development.

E-mail: adel.ziet@univ-setif.dz

ORCID iD: https://orcid.org/0000-0002-1519-4085 